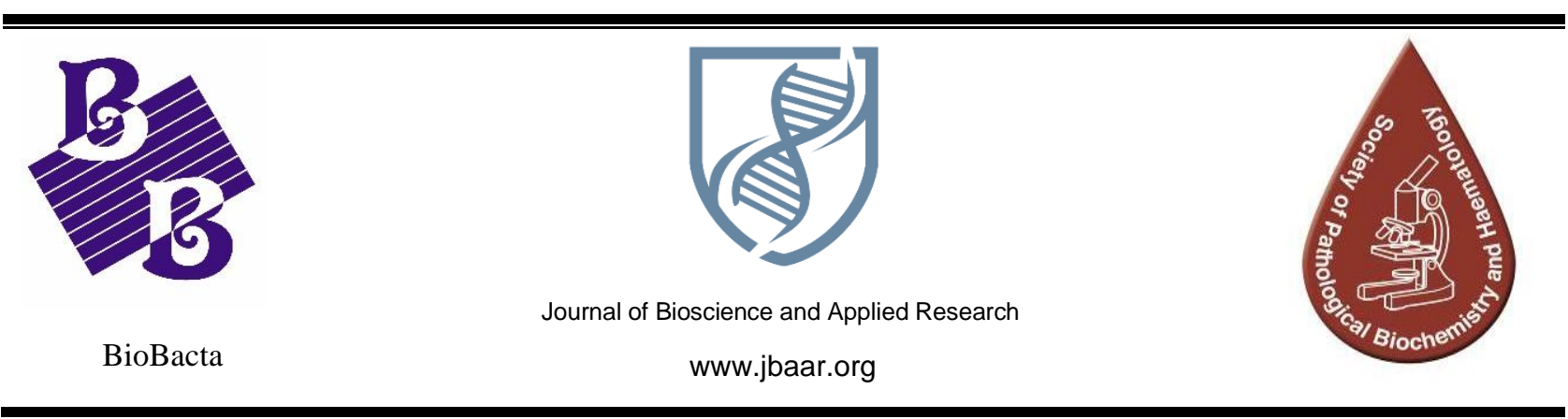

\title{
Salt Tolerance Associated With Molecular Markers in Alfalfa
}

\author{
${ }^{1}$ Clara R. Azzam*, 2 Zainab M. Abd El Naby, and ${ }^{2}$ Nabila A. Mohamed \\ ${ }^{1}$ Department of Cell Research, Field Crop Res. Inst., Agric. Res. Center, Giza, Egypt \\ ${ }^{2}$ Department of Forage Research, Field Crop Res. Inst., Agric. Res. Center, Giza, Egypt \\ *Correspondence: Clara_azzam@yahoo.com
}

\begin{abstract}
Background: Breeding for salinity tolerance in open-pollinated crops depends on broad genetic variation in order to select for vigorous plants under salinity stress. Objective: To compare the yield of some local alfalfa cultivars under saline and non-saline soils and to develop molecular genetic markers associated with salt tolerance using RAPD and ISSR analysis, thereby providing a basis for alfalfa salt-tolerance breeding and research. Methods: A two years field trial was carried out during 2013/14 and 2014/15 in Galbana Village at Sahl El-Tina site., North Sinai Governorate with 13 cuts after establishing period. Three local parental cultivars, nine selected populations for salt stress under different stress levels (three initial EC's :8.73, 10.63 and $12.43 \mathrm{dSm}^{-1}$ ), a new tolerant pop, and three exotic varieties were included in the experiment under initial EC's (10.83). Results: Under Egyptian conditions, local cultivars: Siwa and Ismaelia were qualified as more adapted to salinity stress conditions than the exotic cultivars. New tolerant pop. ranked as the top yielding across all tested parental populations followed by Siwa and Ismaelia tolerant selected populations. New valley population had the lowest fresh, dry and protein yield overall studied populations. The tolerant selected populations were out yielded than their parental cultivars. A total of 16 alfalfa populations were analyzed at the molecular level to develop molecular markers associated with salt tolerance using seven RAPD and five ISSR primers. All primers succeeded to generate reproducible polymorphic DNA products. RAPD primers produced eight positive specific markers and six negative specific markers for salt tolerance in alfalfa population Sinai-1, while ISSR primers produced 12 positive specific markers and six negative specific markers for salt tolerance in alfalfa. The dendrograms were generated using pooled RAPD, ISSR, and the combined analysis of their data divided the alfalfa populations into two main clusters. The first cluster consisted of population Sinai 1 alone, while the second one contains all other evaluated populations. Conclusion: The new tolerant pop. could be considered as a new promising population and more adapted to salt stress.
\end{abstract}

Key words: Alfalfa, salt tolerance, Molecular Markers. Received 26/9/2019; Accepted 22/10/2019

\section{INTRODUCTION}

Lucerne, alfalfa (Medicago sativa L.) has been widely sown in productive livestock systems to supply nutritious feed. It produces a high forage yield in a wide range of environments and highly adaptable to different climatic conditions (Moreira and Fageria, 2010). It has other superior DOI: 10.21608/jbaar.2019.110864 forage qualities, and high yields that can be consumed by livestock (Soya et al., 2004; Geren et al., 2009). Alfalfa is famed by its forage value, long-term crop and high digestibility. From these criteria, alfalfa is considered to be the "Queen of Fodder Herbs". High salt stress generally inhibits the growth of plants (Munns and Tester, 2008). 
Islam et al. (2001) reported that salinity may reduce the crop yield by upsetting water and the nutritional balance of plants. Alfalfa was as tolerant as barley (Hordeum vulgare L.) and cotton (Gossypium spp.), however, the growth of alfalfa was still retarded in saline conditions (Munns, 2005). Salinity had a great effect on the forage and dry yield of three alfalfa cultivars grown at Sahl El-Tina under saline-soil conditions. Alfalfa can be successfully grown on most soils, and can tolerate some level of salinity during the germination stage, but once established, it tolerates higher levels of salinity up to $8 \mathrm{dSm}^{-1}$, (Sheard, 2007, Shaban and ElSherief, 2007 and Abd El-Naby et al., 2013). Abd El-Naby et al. (2013) reported that breeding for salinity tolerance in open-pollinated crops depends on broad genetic variation in order to selection for vigorous plants under salinity stress. AL-Khatib et al. (1993) reported that select highly salt- tolerant genotypes between and within cultivars could be expected to provide useful materials for further breeding programs.

Compared with conventional phenotyping methods, molecular markers have numerous advantages as they are easily detectable and stable in plant tissues regardless of environmental influences (Reddy et al., 2002). Molecular markers can be identified by a range of molecular techniques such as restriction fragment length polymorphisms (RFLPs), randomly amplified polymorphic DNAs (RAPDs), amplified fragment length polymorphism (AFLP), DNA amplification fingerprinting (DAF), sequence characterized amplified regions (SCARs), microsatellites (Simple Sequence Repeat) (SSR) etc, (Lin et al., 1996). DNA molecular marker technology has been applied to screen and identify salt-tolerant alfalfa germplasm and analyze genetic diversity. Domestic and foreign scholars have successfully applied simple sequence repeat (Diwan et al., 1997; Mengoni et al., 2000; Liu et al., 2006) and amplified fragment length polymorphism marker techniques to analyze the genetic diversity of different salt-tolerant cultivars of alfalfa (Julier et al., 2003). Random amplified polymorphic DNA (RAPD) technology is frequently used in tested germplasm, variety identification, polymorphism analysis, and breeding assistance. Also, there are several DNA analytical procedures that have been used to identify, characterize and determine genetic diversity among cultivars. They are a reliable method of genetic fingerprinting and have been successfully used for characterization and evaluation of genetic relationships in several species (Neqi et al., 2000). Inter simple sequence repeat marker (ISSR) is highly polymorphic and is useful in studies of genetic diversity, genome mapping, and evolutionary biology (Reddy et al., 2002).

The present study was carried out to compare the yield of some local alfalfa cultivars under saline and non-saline soils and to test the performance of the new population (Sinai-1) related to its parents under the same conditions. Moreover, to develop molecular genetic markers associated with salt tolerance using RAPD and ISSR analysis, thereby providing a basis for alfalfa salt-tolerance breeding and research.

\section{MATERIALS AND METHODS}

An experiment was conducted in this study; field experiment was carried out, in sandy clay loamy soil and salty soil, in a private farm at Gelbana, East Suez Canal, North Sinai Governorate during two successive seasons from $10^{\text {th }}$ March 2014 to $11^{\text {th }}$ June 2015. Three Egyptian alfalfa cultivars, i.e., Ismaelia, New Valley and Siwa with a new promising population (Sinai-1) produced by Abd El-Naby et al. (2013) three parental alfalfa cultivars, Ismaelia, New valley, and Siwa, and three exotic varieties, CUF 101, Siriver and US storm, were tested under initial levels of salinity $10.83 \mathrm{dSm}^{-1}$, as shown in Table 1. The soil of experimental field was subjected to the continuous leaching process. After leaching EC level was decreased to $7.30 \mathrm{dSm}^{-1}$ then seeds 
were sown. The experiment was laid out in a randomized complete block design with four replications. The plot area was $2 \times 3 \mathrm{~m}^{2}$ and $1 \mathrm{~m}$ between populations. Each variety was seeded at the rate of $30 \mathrm{~g} / \mathrm{plot}$ (20 $\mathrm{kg} / \mathrm{fed}$.). Super phosphate $\left(15.5 \% \mathrm{P}_{2} \mathrm{O}_{5}\right)$ was applied at a rate of $200 \mathrm{~kg} \mathrm{fed}^{-1}$ during tillage then $100 \mathrm{~kg}$ superphosphate was added every four months. Urea $(46 \% \mathrm{~N})$ was applied as $\mathrm{N}$ fertilizer at a rate of $30 \mathrm{~kg} \mathrm{~N} \mathrm{fed}^{-1}$ on three equal doses after 21,42 and 62 days from planting. Potassium sulphate $\left(48 \% \mathrm{~K}_{2} \mathrm{O}\right)$ was applied at a rate of $100 \mathrm{~kg} \mathrm{fed}^{-1}$ with two doses, after 21 and 42 days, and then 50 $\mathrm{kg} \mathrm{fed}^{-1}$ were added every four months. The first irrigation applied eight days after sowing. The following irrigations applied at ten days in summer and fifteen days in winter. At each cut, data were recorded for 10 randomly plants to estimate some agronomic traits such as plant height $\mathrm{cm}$, a number of tillers per plant, and crude protein yield as average overall cuts also, fresh forage and dry yield (t.fed ${ }^{-1}$ ) as total cuts. Alfalfa was harvested sixteen times, the first, second and third cuts were ignored (established period), the yield was evaluated over thirteen cuts after an established period (125 days) from sowing then, populations left for harvesting and set seeding.

Dry matter percentage, where dry matter percentage was determined from random samples $200 \mathrm{~g}$ from each plot, after drying in the oven at $70^{\circ} \mathrm{C}$. Some physical and chemical properties of the soil of the experimental site are presented in

Table 2.

Table (1): Population codes as will be referred and its characterization

\begin{tabular}{|l|l|}
\hline Population codes & \multicolumn{1}{c|}{ characterization } \\
\hline P1 & Ismailia 1-1: selected under initial EC=8.73 \\
P3 & New Valley -1: selected under initial EC=8.73 \\
P4 & Siwa-1: selected under initial EC=8.73 \\
Ismailia 1-2: selected under initial EC=10.63 \\
P6 & New Valley -2: selected under initial EC=10.63 \\
P7 & Siwa -2: selected under initial EC=10.63 \\
P8 & Ismailia 1-3: selected under initial EC=12.43 \\
P9 & New Valley -3: selected under initial EC=12.43 \\
P10 & Siwa -3: selected under initial EC=12.43 \\
P11 & Ismailia 1: Local parental control \\
P12 & New Valley: Local control \\
P13 & Siwa: parental Local parental control \\
P14 & New tolerant pop.: Selected per ECs by Abd El-Naby et al. (2013) \\
P15 & CUF 101: Exotic variety \\
P16 & US Storm: Exotic variety \\
\end{tabular}

Table (2): Some physical and chemical soil characteristics of the experimental site

\begin{tabular}{|c|c|c|c|c|c|c|}
\hline \multicolumn{7}{|c|}{ Soil characteristic } \\
\hline \multirow{2}{*}{$\begin{array}{c}\text { Particle size } \\
\text { distribution \% }\end{array}$} & Coarse sand & Fine sand & \multicolumn{2}{|c|}{ Silt } & Clay & $\begin{array}{l}\text { Textural } \\
\text { class }\end{array}$ \\
\hline & 2.16 & 65.83 & \multicolumn{2}{|c|}{10.60} & 21.41 & \multirow{4}{*}{ Sandy clay } \\
\hline \multirow{3}{*}{$\begin{array}{l}\text { Chemical } \\
\text { properties }\end{array}$} & pH & \multicolumn{3}{|c|}{ EC dS/m $(1: 5)$} & & \\
\hline & $\begin{array}{c}\text { (suspension } \\
1: 2.5 \text { ) }\end{array}$ & Initial & \multicolumn{2}{|c|}{ After leaching } & $\begin{array}{c}\text { Organic } \\
\text { matter }(\%)\end{array}$ & \\
\hline & $\mathbf{8 . 0 7}$ & 10.83 & \multicolumn{2}{|c|}{7.30} & 0.42 & \\
\hline \multirow{3}{*}{$\begin{array}{l}\text { Available macro- } \\
\text { nutrients (mg L-1) }\end{array}$} & \multicolumn{2}{|c|}{$\mathbf{N}$} & \multicolumn{2}{|c|}{$\mathbf{P}$} & \multicolumn{2}{|c|}{$\mathbf{K}$} \\
\hline & Before sowing & $\begin{array}{c}\text { After } \\
\text { sowing }\end{array}$ & $\begin{array}{l}\text { Before } \\
\text { sowing }\end{array}$ & $\begin{array}{c}\text { After } \\
\text { sowing }\end{array}$ & Before sowing & After sowing \\
\hline & 37.0 & 50.23 & 3.69 & 3.37 & 188 & 172 \\
\hline
\end{tabular}




\section{Statistical analysis}

The combined analyses of means for all studied traits were subjected to regular statistical analysis of variance of the split plot design (SPD) according to Gomez and Gomez, (1984). SAS 9.2 (2004) Software was used for statistical analysis. Mean comparison was performed using the least significant difference (L.S.D.) at 0.05 level of probability.

\section{MOLECULAR GENETIC MARKERS USING RANDOM AMPLIFIED POLYMORPHIC DNA (RAPD) AND INTER SIMPLE SEQUENCE REPEATS (ISSR)}

A total of 16 alfalfa populations Table 1 were analyzed at the molecular level to develop molecular markers associated with salt tolerance by using seven pre-screened RAPD primers and five pre-screened ISSR primers. All primers succeeded to generate reproducible polymorphic DNA products. Table 3 lists the base sequences of these DNA primers for both RAPD and ISSR markers that produced informative polymorphic bands.

DNA was extracted from leaves of two weeks old seedlings, $1.5 \mathrm{ml}$ of extraction buffer (Tris- $\mathrm{HCl} 100$ mM, pH 7; EDTA $100 \mathrm{mM}$, pH 7; $\mathrm{NaCl} 3 \mathrm{M}$ ) and SDS at a final concentration of $1 \%$ were added. Each sample was shaken and $1.5 \mathrm{ml}$ of equilibrated phenol was added. The phases were separated by centrifugation at $13,000 \mathrm{rpm}$ for $30 \mathrm{~min}$ then $500 \mathrm{ml}$ of supernatant transferred to $1.5 \mathrm{ml}$ eppendorf and 2 volume of $100 \%$ ethanol and $50 \mathrm{ml}$ of $3 \mathrm{M}$ sodium acetate were added to the supernatant for DNA precipitation. The pellets were washed with $70 \%$ ethanol and re-suspended in $200 \mathrm{ml}$ of Tris EDTA. Samples were treated with RNase. DNA concentrations and their purity were determined by taking A260 and A260/A280 values in UNICO UV2000 Spectrophotometer (Shanghai, China). The amplification reaction was carried out according to the protocol proposed by Williams et al. (1990). Polymerase chain reaction (PCR) was performed in Gradient Cycler (BioRAD, USA), the reaction mixture for PCR $(25 \mu \mathrm{l})$ consisted of 1X Taq assay buffer (Bangalore Genei Pvt. Ltd., Bangalore, India), $200 \mu \mathrm{M}$ of each dNTP (Promega, Madison, USA), $0.2 \mu \mathrm{M}$ of primer (Bio Basic Inc, Canada), 10 ng genomic DNA and $1 \mathrm{U}$ Taq polymerase (Promega, Madison, USA), The PCR protocol was as follows: initial denaturation at $94^{\circ} \mathrm{C}$ for $4 \mathrm{~min}, 35$ cycles' $94^{\circ} \mathrm{C} / 30 \mathrm{~s}, 37^{\circ} \mathrm{C} / 45 \mathrm{~s}$, $72^{\circ} \mathrm{C} / 60 \mathrm{~s}$ and a final extension at $72^{\circ} \mathrm{C} / 10 \mathrm{~min}$. the amplification product was checked on $1.25 \%$ agarose gels in $0.5 \mathrm{X}$ TBE buffer and visualized by staining with $0.01 \%$ ethidium bromide. For comparison of molecular size of amplicons $100 \mathrm{bp}$ ladder (GeneRuler 100bp Plus DNA Ladder and SibEnzyme 100bp) were also run along with each genotype. Gels were photographed under UV light and score using a gel documentation system manufactured by Alpha Ease FC (Alphimager Tm 2200), U.S.A. Only reproducible and distinct bands were scored as $1 / 0$ (presence /absence) for data analysis. The data of RAPD and ISSR analyses were entered in a computer file as binary matrices. Similarity coefficients were calculated according to Dice matrix (Nei and Li, 1979).

Genetic distances were calculated and constructions of the dendrogram trees were performed using the unweighted pair group method based on the arithmetic mean (UPGMA) as implemented in the SPSS Program Version 14.

Table 3: List of the primer names and their nucleotide sequences used in this study in RAPD and ISSR molecular types.

\begin{tabular}{|c|cc|}
\hline $\begin{array}{c}\text { Molecular } \\
\text { Type }\end{array}$ & Primer Codes & Sequence ${ }^{\mathbf{5}} \rightarrow \mathbf{3}$ \\
\hline & OP-A08 & GTGACGTAGG \\
& OP-A11 & CAATCGCCGT \\
RAPD & OP-B05 & TGCGCCCTTC \\
& OP-B15 & GGAGGGTGTT \\
& OP-B20 & GGACCCTTAC \\
& OP-C07 & GTCCCGACGA \\
& OP-C17 & TTCCCCCCAG \\
\hline & HB-10 & GAG AGAGAGAGACC \\
ISSR & HB-11 & GTGTGTGTGTGTGTGCC \\
& HB-12 & CACCACCACGC \\
& HB-14 & CTCCTCCTCGC \\
& HB-15 & GTGGTGGTGGC \\
\hline
\end{tabular}




\section{RESULTS AND DISCUSSION}

\section{EFFECT OF SALT STRESS ON ALFALFA POPULATIONS}

The results of the analysis of variance of the 13 cuts from 16 cuts, 4 replications under salinity stress are shown in Table 4. It can be seen that total fresh forage yield (TFY), total dry yield (TDY), and total protein yield (TPY) were high significant effects.

The tolerant selected populations with code numbers from P1 to P9 exceeded higher fresh, dry and protein yield under salinity stress with mean average (35.12, 8.79 and 2.01 t.fed $\left.^{-1}\right)$ than their parental cultivars (P10, $\mathrm{P} 11$, and P12) with mean average $(33.05,8.45$ and 1.97 t.fed $\left.{ }^{-1}\right)$. The exotic populations (P14, P15, and P16) produced less fresh, dry and protein yield than all the studied populations with mean average $(32.90,8.44$, and $1.85 \mathrm{t}$. $\left.\mathrm{fed}^{-1}\right)$. Populations are varied in their performance according to saline stress tolerant. Under Egyptian conditions the local cultivars specially Siwa and Ismaelia cultivars indicated the best total fresh, dry, and protein yield than the exotic varieties. Siwa $-1,2$ and 3 showed the highest yield production over all tolerant selected populations under salt stress condition Table 4. New tolerant pop. (P13) gained the top yield production of fresh, dry and protein $(38.72,10.38$ and $2.55 \mathrm{t} / \mathrm{fed}$, respectively) followed by Siwa-3 (P9) tolerant selected pop. (38.59, 9.54 and $2.28 \mathrm{t} / \mathrm{fed}$, respectively) and Ismaelia 1-3 pop. (P7) with (36.72, 9.48 and $2.20 \mathrm{t} / \mathrm{fed}$, respectively). Monirifar et al. (2004) found phenotypic variation between some Azarbaijan alfalfa cultivars at different salinity levels and reported that changes in forage yield resulting from saline stress. These results were in harmony with Longenecker and Lyerly (1974), who reported that alfalfa has been characterized as tolerant to salts with a range of EC values from 6.0 to $8.0 \mathrm{dSm}^{-1}$ at which some reduction in growth characters and yields might occur. Alfalfa cultivars were varied in tolerant to salt stress, considerable variation in salt tolerance appears among and within alfalfa populations (Allen et al., 1985; Rumbaugh and Pendery, 1990). Abd El- Naby et al. (2013) mentioned that Siwa and Ismaelia local cultivars are moderate to salinity stress.

Table (4): Comparisons of total fresh, dry and protein yield of 16 alfalfa populations under salinity stress

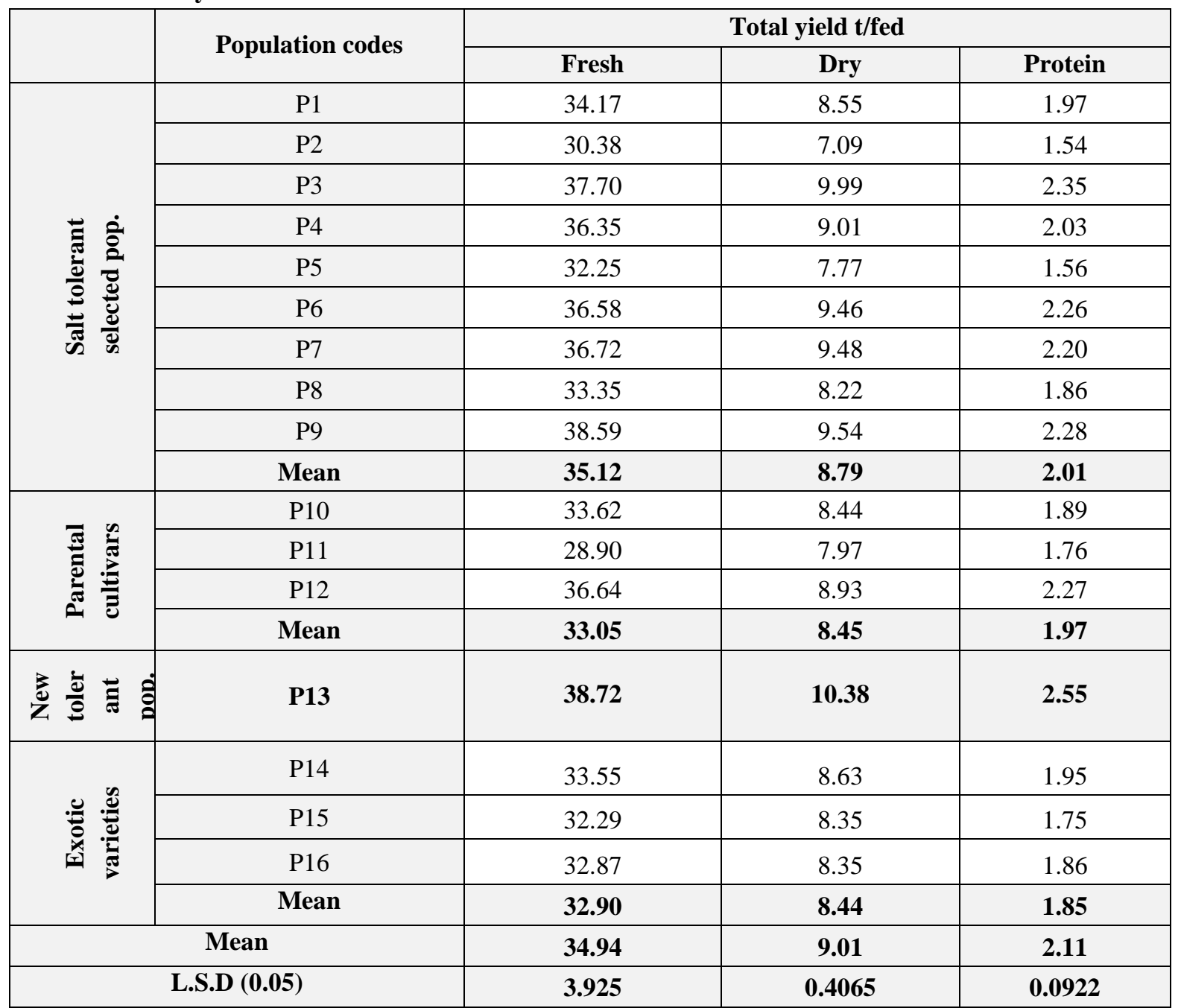


Figures. 1 and 2 showed the effect of salinity effects on plant height and number of tillers $/ \mathrm{m}^{2}$ over all tested populations and over cuts. Tolerant promised population (P 13) indicated the best performances under the salt stress followed by Siwa-3 and Siwa-2 tolerant selected populations (P 9 and P6) for plant height (62, 62 and $60 \mathrm{~cm}$ ), whereas tolerant selected pop. New valley-1, 2 and exported cultivar Siriver were the shortest with the same height $(56 \mathrm{~cm})$. The highest number of tillers $/ \mathrm{m}^{2}$ recorded for new promised pop., Siwa-1 and Siwa-3 populations $(283,283$ and 282 tiller $/ \mathrm{m}^{2}$ ). New valley local cultivar (P11) had the lowest tillers number per $\mathrm{m}^{2}$ (232 tillers). Siwa local cultivar was a more adapted population to salt stress followed by Ismaelia cultivar (Abd El-Naby et al., 2013).

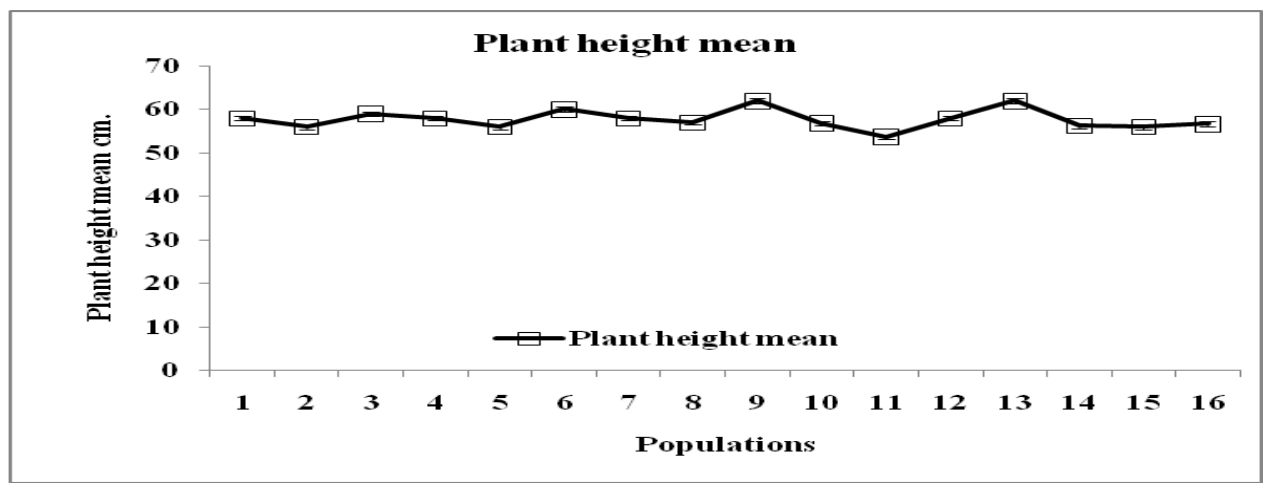

Figure.1: Average of plant height over all cuts per each population under three salinity Levels $( \pm \mathrm{SE})$.

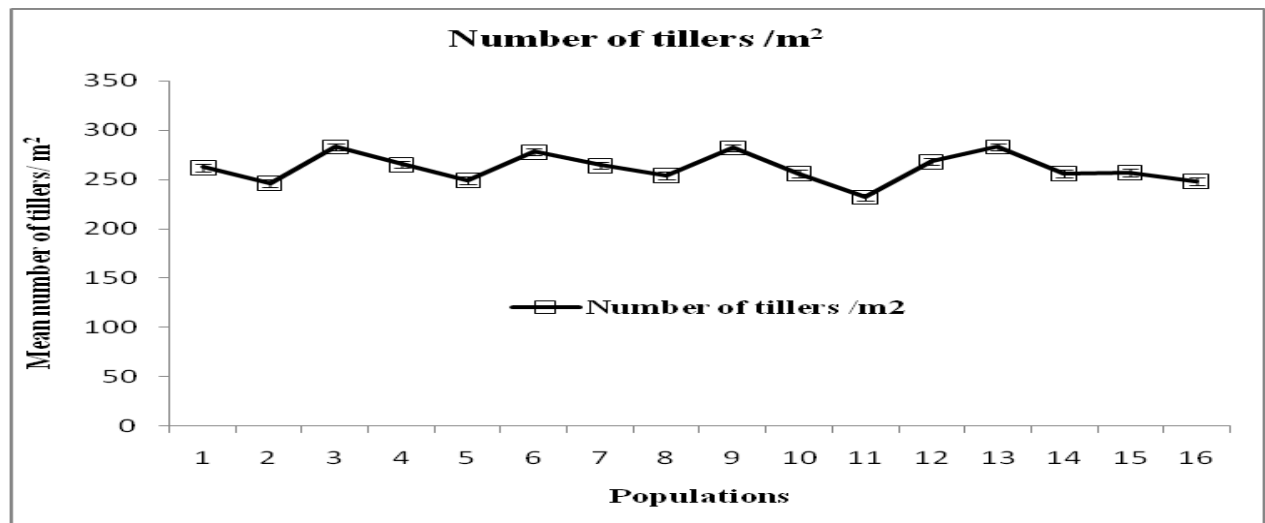

Figure .2 : Average of tillers number $/ \mathrm{m}^{2}$ over all cuts per each population under salinity stress $( \pm \mathrm{SE})$.

\section{MOLECULAR MARKERS RELATED SALINITY STRESS USING RAPD}

RAPD-PCR technique was used to develop molecular markers for salinity using seven 10-mer random primers. All primers successfully amplified DNA fragments for all genotypes and produced different bands number ranging from 3 to 14 bands. Six of them showed some molecular markers for salinity tolerance. Primer OP-A08 showed one band with molecular sizes of $582 \mathrm{bp}$ presented in the salt tolerant population Sinai1 and could be considered as a positive molecular marker for salinity tolerance in alfalfa. Whereas one band with a molecular size of $334 \mathrm{bp}$ absented in the tolerant population Sinai-1, it could be considered as a negative molecular marker for salinity tolerance in alfalfa plants (Figure. 3).

Also, primer OP-B05 showed two bands with a molecular size of 665 and $595 \mathrm{bp}$, which presented in the salt-tolerant population Sinai-1, while it was absent in all other populations. So, these bands can be used as a positive molecular markers for salinity tolerance in alfalfa plants.

Primer OP-B15 showed one band with a molecular size of $1482 \mathrm{bp}$, which presented in the salt tolerant population Sinai-1, it could be considered as a positive molecular marker for salinity tolerance in alfalfa, while one band with a molecular size of $280 \mathrm{bp}$, that was 
absent in the tolerant population Sinai-1, and could be considered as a negative molecular marker for salinity tolerance in alfalfa plants.

Primer OP-B20 showed one band with a molecular size of $399 \mathrm{bp}$, which presented in the salt-tolerant population Sinai-1 and could be considered as a positive molecular marker for salinity tolerance in alfalfa, while four bands with molecular sizes of 1803, 1410, 1204 and $836 \mathrm{bp}$ were absent in the salt-tolerant population Sinai-1 and appeared in all other populations, and could

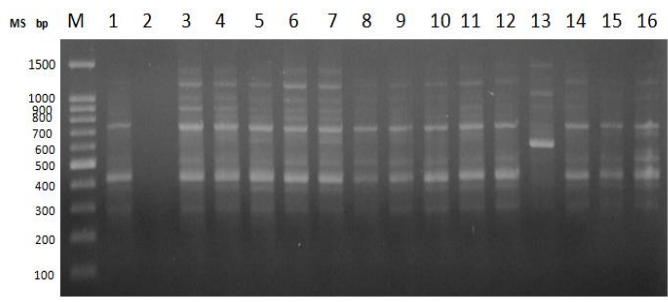

OP-A08

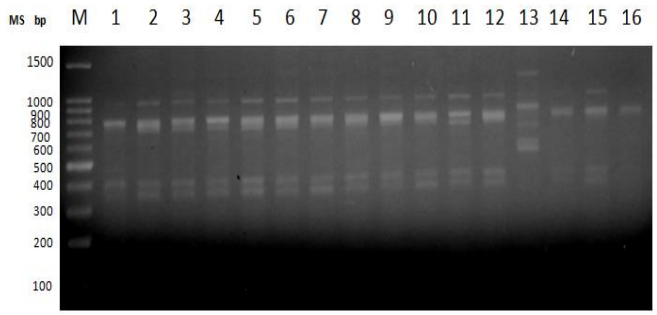

OP-B05

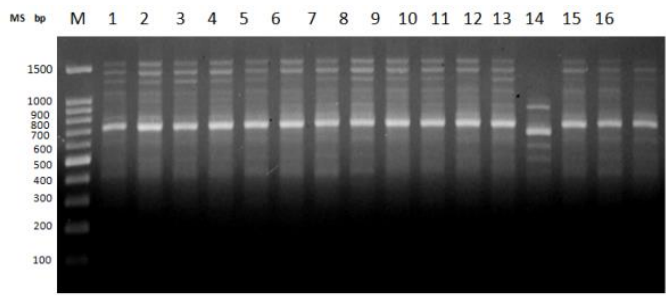

OP-B20 be considered as negative molecular markers for salinity tolerance in alfalfa plants.

Also, primer OP-C07 showed two bands with the molecular size of 2137 and $1835 \mathrm{bp}$, which presented in the salt-tolerant population Sinai-1, while it was absent in all evaluated populations. So, these bands could be used as positive molecular markers for salinity tolerance in alfalfa plants, as well as, the band with a molecular size of $734 \mathrm{bp}$ that appeared with primer OPC17 (Figure. 3).

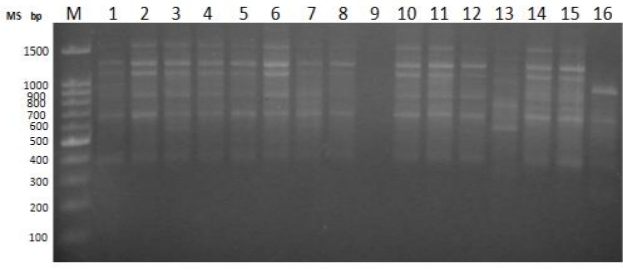

OP-A11

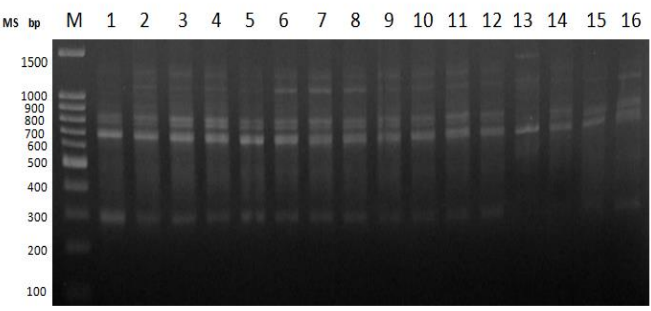

OP-B15

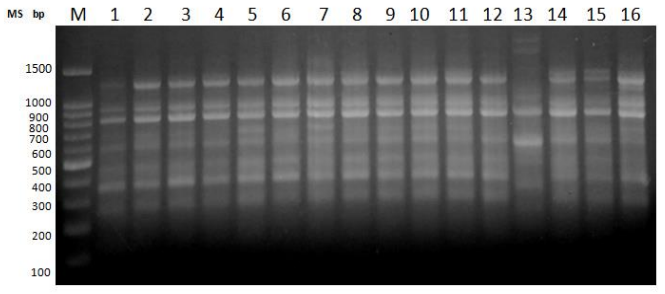

OP-C07

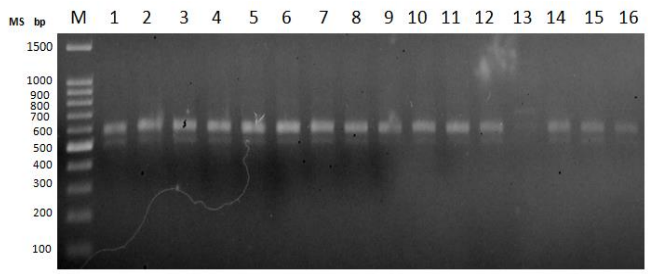

OP-C17

Figure.3: Amplification profile of 16 alfalfa populations, (with the same order as in Table 2) employing primer OP-A08, OP-A11, OP-B05, OP-B15, OP-B20, OP-C07and OP-C17. Note: $M=100$ bp Ladder.

The RAPD derived data were subjected to calculate the genetic similarity as shown in Table 5. The genetic similarity coefficients varied between 0.96 and 0.39 . The minimum GS (Genetic similarity) value derived between populations of Ismailia- 1 and Siwa, while the maximum GS value derived between populations Sinia1 and both of Sea River and US Storm, respectively.

Cluster analysis was conducted to generate a dendrogram elucidating for relationships among alfalfa populations. The dendrogram was generated using pooled RAPD data divided the alfalfa populations into two main clusters (Figure. 4). The first cluster consisted of population Sinai 1 alone, while the second one contained all other evaluated populations.

These results are in agreement with those reported by Fahmy et al. (1997) who used RAPD technique to differentiate between drought tolerant and drought sensitive genotypes of berseem clover (Trifolium 
alexandrinum L.) and obtained two positive molecular markers under stress. Also, Wenzel (1992) emphasized the potential for DNA markers- based diagnosis of abiotic stress tolerance in plants. Echt et al. (1992) reported that RAPD markers appeared to be useful for the rapid development of genetic information in alfalfa. Also, Dias et al. (2004) reported that the RAPD markers were efficient in separating all the accessions analyzed individually. Bortolini et al. (2006) used RAPD molecular markers for white clover, and their results highlighted the high genetic diversity present between the accessions from different origins and breeding status. Also, Azzam et al. (2007) revealed that the chosen RAPD markers are distributed in the peanut genome and may be useful to investigate the genetic diversity among the studied peanut genotypes.

Table (5): Similarity value (Pairwise comparison) of the 16 alfalfa populations based on RAPD data.

\begin{tabular}{|c|c|c|c|c|c|c|c|c|c|c|c|c|c|c|c|}
\hline Population & P 1 & $\mathbf{P 2}$ & P3 & P4 & P5 & P6 & P7 & P8 & P9 & P10 & P11 & P12 & P13 & P14 & P15 \\
\hline $\begin{array}{l}\text { P2 } \\
\text { P3 }\end{array}$ & $\begin{array}{l}0.70 \\
0.85\end{array}$ & O 78 & & & & & & & & & & & & & \\
\hline P4 & 0.86 & 0.82 & 0.92 & & & & & & & & & & & & \\
\hline P5 & 0.88 & 0.77 & 0.93 & 0.94 & & & & & & & & & & & \\
\hline P6 & 0.84 & 0.79 & 0.92 & 0.95 & 0.89 & & & & & & & & & & \\
\hline P7 & 0.79 & 0.73 & 0.85 & 0.86 & 0.84 & 0.86 & & & & & & & & & \\
\hline P8 & 0.82 & 0.79 & 0.83 & 0.86 & 0.85 & 0.86 & 0.89 & & & & & & & & \\
\hline P9 & 0.81 & 0.69 & 0.82 & 0.83 & 0.79 & 0.83 & 0.80 & 0.81 & & & & & & & \\
\hline P10 & 0.84 & 0.76 & 0.92 & 0.88 & 0.87 & 0.88 & 0.88 & 0.81 & 0.88 & & & & & & \\
\hline P11 & 0.83 & 0.75 & 0.88 & 0.89 & 0.86 & 0.89 & 0.84 & 0.80 & 0.84 & 0.94 & & & & & \\
\hline P12 & 0.80 & 0.77 & 0.88 & 0.87 & 0.85 & 0.87 & 0.89 & 0.80 & 0.84 & 0.96 & 0.93 & & & & \\
\hline P13 & 0.58 & 0.41 & 0.63 & 0.56 & 0.57 & 0.59 & 0.58 & 0.60 & 0.49 & 0.58 & 0.57 & 0.56 & & & \\
\hline P14 & 0.79 & 0.61 & 0.78 & 0.79 & 0.80 & 0.76 & 0.81 & 0.79 & 0.75 & 0.84 & 0.77 & 0.82 & 0.56 & & \\
\hline P15 & 0.75 & 0.69 & 0.77 & 0.75 & 0.82 & 0.73 & 0.80 & 0.75 & 0.74 & 0.80 & 0.76 & 0.84 & 0.49 & 0.87 & \\
\hline P16 & 0.64 & 0.56 & 0.61 & 0.65 & 0.66 & 0.62 & 0.64 & 0.67 & 0.68 & 0.61 & 0.60 & 0.62 & 0.39 & 0.59 & 0.62 \\
\hline
\end{tabular}

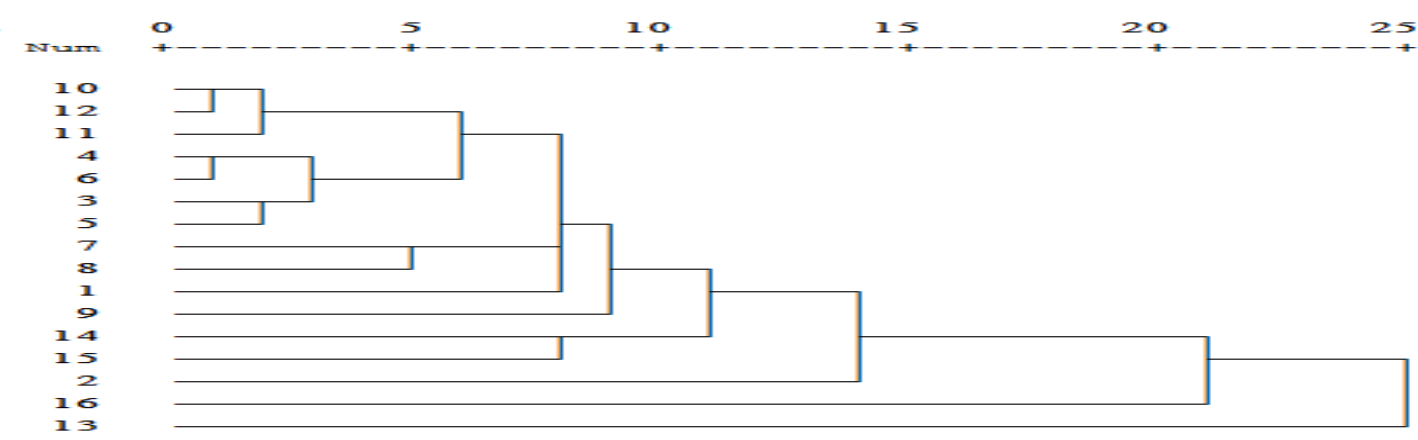

Figure. 4: A dendrogram illustrates the genetic distance among the 16 alfalfa populations based on RAPD data. Where: $1=\mathrm{P} 1,2=\mathrm{P} 2,3=\mathrm{P} 3,4=\mathrm{P} 4,5=\mathrm{P} 5,6=\mathrm{P} 6,7=\mathrm{P} 7,8=\mathrm{P} 8,9=\mathrm{P} 9,10=\mathrm{P} 10,11=\mathrm{P} 11$, $12=\mathrm{P} 12,13=\mathrm{P} 13,14=\mathrm{P} 14,15=\mathrm{P} 15$ and $16=\mathrm{P} 16$

\section{MOLECULAR MARKERS RELATED TO SALINITY STRESS USING ISSR}

ISSR primers analysis was used to obtain molecular genetic markers for salinity tolerance from the 16 populations using five primers (Figure. 5). All ISSR primers succeeded in amplifying DNA fragments. Among the 46 amplified fragments across the five primers, 44 were polymorphic $(95.6 \%)$. Primer HB-10 showed bands with a molecular size of 703, 526, 472 and $422 \mathrm{bp}$, which presented in the tolerant population of Sinai-1, while it was absent in all other populations.
So, these bands could be considered as positive molecular markers for salinity tolerance in alfalfa plants. Also, primer HB-11 gave two bands with a molecular size of 2204 and 1139 bp, which were exclusively present in Sinai-1. So, these bands can be used as positive molecular markers for salinity tolerance in alfalfa plants. While one band with a molecular size of 776 bp was absent in Sinai-1, while it presented in all other tested populations, and could be used as a negative molecular marker for salinity tolerance in alfalfa (Figure. 5). On the other hand, 
Primer HB-12 exhibited one positive and one negative molecular marker for salinity tolerance in alfalfa with a molecular size of 2368 and $507 \mathrm{bp}$, respectively.

Primer HB-15 showed five bands with a molecular size of 1513, 1142, 821, 695 and 294 bp, which were exclusively present in Sinai-1 (the salt-tolerant population). So, these bands can be used as positive molecular markers for salinity tolerance in alfalfa., as well as, four negative molecular markers with 1052 , 768, 570 and 342bp that were absent in Sinai-1 while they presented in all other tested populations, and could be used as negative molecular markers for salinity tolerance in alfalfa (Figure. 5).

The ISSR derived data were subjected to calculate the

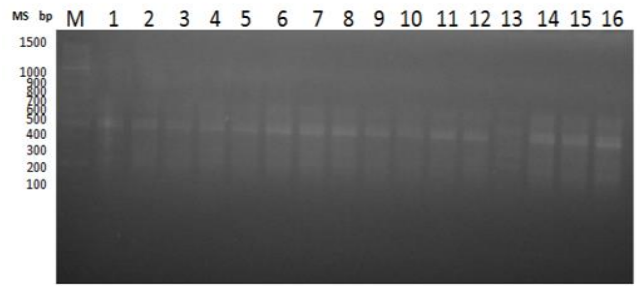

HB-10

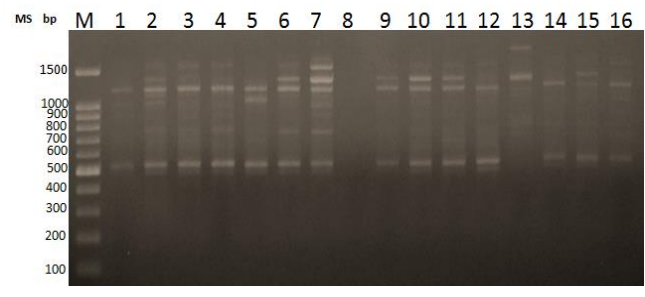

HB-12 genetic similarity Table 7. The genetic similarity coefficients varied between 0.98 and 0.26 . The minimum GS (Genetic similarity) value derived between Sinai-1 population and P1, while the maximum GS value derived between $\mathrm{P} 2$ and $\mathrm{P} 3$, as same as, between P6 and P10 Table 6.

Cluster analysis was conducted to generate a dendrogram elucidating for relationships among alfalfa populations. The dendrogram generated using pooled ISSR data divided the alfalfa populations into two main clusters (Figure. 6). The first cluster consisted of population Sinai 1 alone, while the second one contained all other evaluated populations.

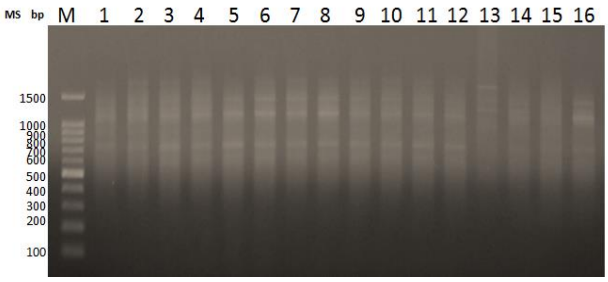

HB-11

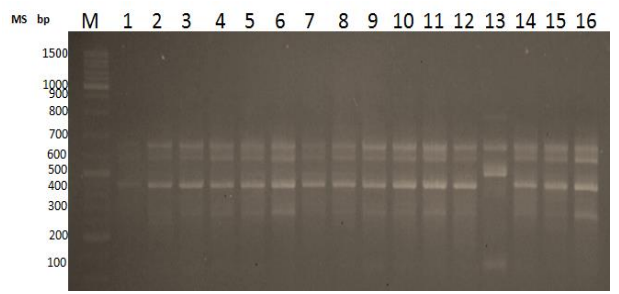

HB-14

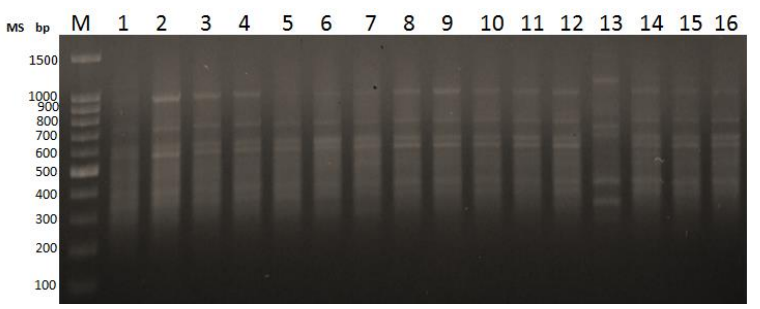

HB-15

Fig 5: Amplification profile of 16 alfalfa population, (with the same order as in Table 2) employing ISSR primer 14A, HB-10, HB-11 and HB-12. Note: M=100 bp Ladder. 
Table (6): Similarity value (Pairwise comparison) of the sixteen alfalfa populations based on ISSR data.

\begin{tabular}{l|lllllllllllllll}
\hline Populations & P1 & P2 & P3 & P4 & P5 & P6 & P7 & P8 & P9 & P10 & P11 & P12 & P13 & P14 & P15 \\
\hline P2 & 0.74 & & & & & & & & & & & & & \\
P3 & 0.72 & 0.98 & & & & & & & & & & & & \\
P4 & 0.82 & 0.92 & 0.90 & & & & & & & & & & & \\
P5 & 0.68 & 0.79 & 0.82 & 0.81 & & & & & & & & & & \\
P6 & 0.68 & 0.88 & 0.91 & 0.81 & 0.87 & & & & & & & & & \\
P7 & 0.77 & 0.86 & 0.89 & 0.84 & 0.81 & 0.89 & & & & & & & & & \\
P8 & 0.72 & 0.67 & 0.70 & 0.69 & 0.67 & 0.72 & 0.75 & & & & & & & & \\
P9 & 0.69 & 0.80 & 0.83 & 0.77 & 0.79 & 0.88 & 0.82 & 0.78 & & & & & & & \\
P10 & 0.65 & 0.86 & 0.88 & 0.78 & 0.89 & 0.98 & 0.87 & 0.74 & 0.91 & & & & & & \\
P11 & 0.67 & 0.78 & 0.81 & 0.75 & 0.86 & 0.91 & 0.80 & 0.76 & 0.88 & 0.93 & & & & \\
$\mathbf{P 1 2}$ & 0.71 & 0.82 & 0.80 & 0.74 & 0.76 & 0.81 & 0.79 & 0.74 & 0.82 & 0.83 & 0.80 & & & & \\
$\mathbf{P 1 3}$ & 0.26 & 0.37 & 0.41 & 0.38 & 0.44 & 0.44 & 0.38 & 0.41 & 0.42 & 0.44 & 0.46 & 0.38 & & & \\
$\mathbf{P 1 4}$ & 0.72 & 0.68 & 0.67 & 0.70 & 0.68 & 0.68 & 0.71 & 0.76 & 0.73 & 0.69 & 0.71 & 0.85 & 0.41 & \\
$\mathbf{P 1 5}$ & 0.69 & 0.75 & 0.73 & 0.72 & 0.75 & 0.74 & 0.77 & 0.67 & 0.70 & 0.76 & 0.73 & 0.82 & 0.42 & 0.88 \\
$\mathbf{P 1 6}$ & 0.70 & 0.71 & 0.74 & 0.68 & 0.80 & 0.76 & 0.78 & 0.74 & 0.76 & 0.77 & 0.79 & 0.83 & 0.44 & 0.84 & 0.86 \\
\hline
\end{tabular}

These results are in agreement with those Wei (2004) who reported that DNA fingerprinting can be applied to variety identification and genetic diversity evaluation of Medicago sativa. Hassan (2005) reported that ISSR marker is the best choice for the evaluation of diversity and assessing the genetic relationships between $M$. oleifera and $M$. pregrina genotypes with high accuracy. Also, Said (2005) stated that ISSR markers were useful tools to assess the genetic variations in Capparis spp. (caper) and Solenostemma arghel (arghel) species, which is considered as an important prerequisite for the improvement of these species and for the conservation of their germplasm.

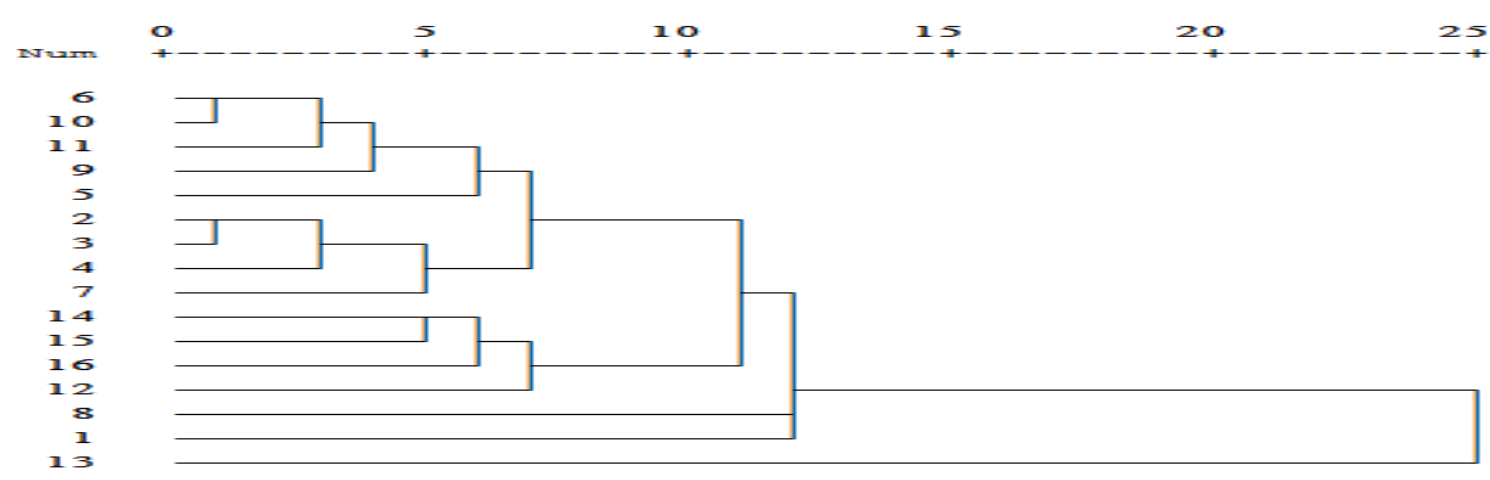

Figure. 6: A dendrogram illustrates the genetic distance among the sixteen alfalfa populations based on ISSR data. Where: $1=\mathrm{P} 1,2=\mathrm{P} 2,3=\mathrm{P} 3,4=\mathrm{P} 4,5=\mathrm{P} 5,6=\mathrm{P} 6,7=\mathrm{P} 7,8=\mathrm{P} 8,9=\mathrm{P} 9,10=\mathrm{P} 10$, $11=\mathrm{P} 11,12=\mathrm{P} 12,13=\mathrm{P} 13,14=\mathrm{P} 14,15=\mathrm{P} 15$ and $16=\mathrm{P} 16$

\section{COMBINED GENETIC RELATIONSHIPS}

Genotypes distribution on the consensus tree according to the banding patterns of ISSR shuffled from that based on RAPD (banding patterns) consensus tree due to the coverage of each technique to different parts of the genome. So that it is better to use a combination of the two techniques of the banding patterns to cover as much as possible of the genome that will increase the validity of the consensus tree. The similarity matrices resulting from the combined DNA markers data were performed to generate correct relationships based on large and different genome regions.

The RAPD's and ISSR's combined data were close to RAPD data and showed genetic similarity ranged between 0.40 and 0.92 .

The closest relationship obtained by the RAPD's and ISSR's combined data analysis was between P10 and both P6, P11 and P12, as well as, between P3 and P6. On the other hand, the lowest genetic similarity of the RAPD's and ISSR's combined data analysis was $40 \%$ 
and occurred between Sinai-1and both P2 and P16, as shown in Table 7.

The dendrogram built on the basis of combined data from RAPD and ISSR analysis represents the genetic distances among the 16 alfalfa populations (Figure.

7). The combined marker analysis dendrogram was more comparable to that obtained separately by RAPD and ISSR analysis. The dendrogram separated alfalfa populations into two main clusters. The first cluster included only Sinai-1, the salt-tolerant population, while the second one comprised all other evaluated populations, as shown in Figure. 7.

Table (7): Similarity value (Pairwise comparison) of the sixteen alfalfa populations based on RAPD and ISSR data.

\begin{tabular}{l|lllllllllllllll}
\hline Population & P 1 & P2 & P3 & P4 & P5 & P6 & P7 & P8 & P9 & P10 & P11 & P12 & P13 & P14 & P15 \\
\hline P2 & 0.72 & & & & & & & & & & & & & \\
P3 & 0.81 & 0.85 & & & & & & & & & & & & \\
P4 & 0.85 & 0.85 & 0.91 & & & & & & & & & & & \\
P5 & 0.81 & 0.78 & 0.89 & 0.90 & & & & & & & & & & \\
P6 & 0.79 & 0.82 & 0.92 & 0.91 & 0.89 & & & & & & & & & \\
P7 & 0.78 & 0.78 & 0.86 & 0.85 & 0.83 & 0.87 & & & & & & & & \\
P8 & 0.79 & 0.75 & 0.79 & 0.81 & 0.79 & 0.82 & 0.84 & & & & & & & \\
P9 & 0.77 & 0.73 & 0.82 & 0.81 & 0.79 & 0.85 & 0.81 & 0.80 & & & & & & \\
P10 & 0.78 & 0.79 & 0.91 & 0.85 & 0.88 & 0.92 & 0.88 & 0.79 & 0.89 & & & & & \\
P11 & 0.78 & 0.76 & 0.86 & 0.85 & 0.86 & 0.90 & 0.83 & 0.79 & 0.86 & 0.92 & & & & \\
P12 & 0.77 & 0.79 & 0.86 & 0.83 & 0.82 & 0.85 & 0.86 & 0.78 & 0.83 & 0.92 & 0.89 & & & \\
P13 & 0.47 & 0.40 & 0.55 & 0.50 & 0.52 & 0.53 & 0.50 & 0.54 & 0.46 & 0.53 & 0.53 & 0.50 & & \\
P14 & 0.77 & 0.64 & 0.74 & 0.76 & 0.76 & 0.73 & 0.77 & 0.78 & 0.74 & 0.79 & 0.75 & 0.83 & 0.50 & \\
P15 & 0.73 & 0.71 & 0.76 & 0.74 & 0.79 & 0.73 & 0.79 & 0.72 & 0.72 & 0.79 & 0.75 & 0.83 & 0.46 & 0.85 \\
P16 & 0.66 & 0.62 & 0.66 & 0.66 & 0.71 & 0.67 & 0.70 & 0.69 & 0.71 & 0.67 & 0.67 & 0.70 & 0.41 & 0.69 & 0.71 \\
\hline
\end{tabular}

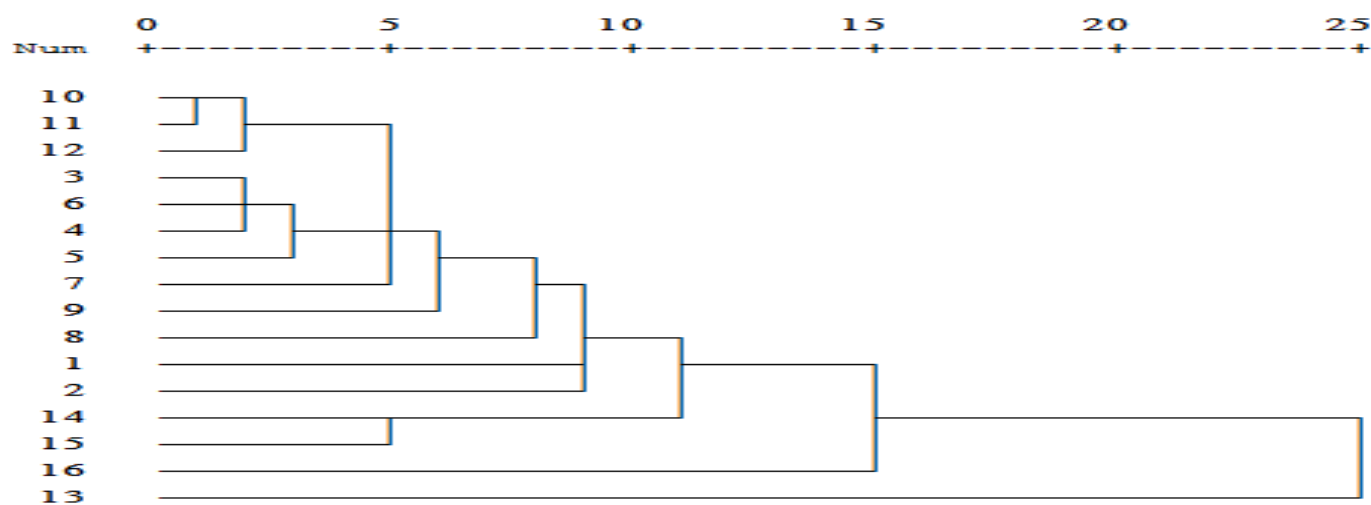

Figure. 7: A dendrogram illustrates the genetic distance among the sixteen alfalfa populations based on RAPD and ISSR data. Where: $1=\mathrm{P} 1,2=\mathrm{P} 2,3=\mathrm{P} 3,4=\mathrm{P} 4,5=\mathrm{P} 5,6=\mathrm{P} 6,7=\mathrm{P} 7$, $8=\mathrm{P} 8,9=\mathrm{P} 9,10=\mathrm{P} 10,11=\mathrm{P} 11,12=\mathrm{P} 12,13=\mathrm{P} 13,14=\mathrm{P} 14,15=\mathrm{P} 15$ and $16=\mathrm{P} 16$

\section{CONCLUSION}

Breeding for salinity problems by producing moderate populations to salt stress with low depressing in productivity was and still the first important objective of alfalfa breeders. The present findings revealed variations among the ten tolerant selected alfalfa populations compared with their local parents and three exported populations. The highest fresh yield was found for new tolerant promised pop. (P13). New valley local cultivar was more sensitive to salinity stress. These results confirm the influential of individual selection of vigorous between and within alfalfa populations under saline soil. Consequently, the selection will be more advantageous for fresh forage yield and thus for dry forage yield under fertile soil. Under Egyptian conditions, local cultivars were out yielded than the exotic populations. New tolerant pop. could be considered as a new promising population and more adapted to salt stress. However, further researches are required to test this new population under different environmental conditions before register. 


\section{REFERENCES}

Abd El-Naby, Zeinab, M, Nabila, A. Mohamed and Kh. A. Shaban (2013). Estimation of soil Fertility and Yield productivity of three alfalfa (Medicago sativa 1.) cultivars under Sahl El-Tina saline soils conditions. Life Sci. J; 10 (1):20822095.

Allen S. G., A. K.Dobrenz, M. H.Schonhorst and J. E. Stoner (1985). Heritability of $\mathrm{NaCl}$ tolerance in germinating alfalfa Seeds. Agron. J.77, 99101.10.2134/agronj

1985. $00021962007700010023 x$

Al-khatib M, T. Mc Neilly and J.Collins (1993). The potential of selection and breeding for improved salt tolerance in lucerne (Medicago sativa L.). Euphytica. 65: 43-51.

Azzam, Clara R., S. A. Azer, M. M. A. Khalifa and M.F. Abol-Ela (2007): Characterization of peanut mutants and molecular markers associated with resistance to pod rot diseases and aflatoxin contamination by RAPD and ISSR. Arab J. of Biotech., 10 (2):301-320.

Bortolini, F., M. Dall'Agnol and Maria T. SchifinoWittmann (2006). Molecular Characterization of the USDA White Clover (Trifolium repens L.) Core Collection by RAPD Markers. Genetic Resources and Crop Evolution, 53: 1081-1087.

Dias, P. M. B., M. Dall'agnol and M. T. S. Wittmann (2004). Genetic diversity in the Brazilian species of Adesmia DC (Leguminosae) as assessed by RAPD. Plant Genetic Resources, 2:43-50.

Diwan, N., A, A. Bhagwat, G. B. Bauchan and P. B. Cregan (1997). Simple sequence repeat DNA markers in alfalfa and perennial and annual Medicago species. Genome 40: 887-895.

Echt, C. S., L. A. Erdahl and T. J. McCoya (1992). Genetic segregation of random amplified polymorphic DNA in diploid cultivated alfalfa. Genome, 35: 84-87.

Fahmy, Eman, M., F. M. Abdel-Tawab, A. Belal and Wafaa M. Sharawy (1997). Marker-assisted selection for drought tolerance in berSeam clover (Trifolium alexandrinum L.) J. Union Arab. Biol., Cairo, 4: 303-328.

Geren, H., B. Kir, G. Demiroglu and Y.T. Kavut (2009). Effects of different soil textures on the yield and chemical composition of alfalfa (Medicago sativa L.) cultivars under mediterranean climate conditions. Asian Journal of Chemistry, 21 (7), p: 5517-5522.

Gomez, K. A. and A. A. Gomez (1984), Statistical Procedures for Agricultural Research. $2^{\text {nd }}$ Edn. John Wiley and Sons Inc. New York, pp: 95109.

Hassan, A. M. H. (2005). Identification of molecular markers for some morphological and biochemical characters in some medicinal plants. MSc. Thesis, Fac. Agric. Ain Shams Univ., Egypt.
Islam, M.R., M.A.R.Bhuiyan, B.Prasad and M.A. Quddus (2001). Salinity effect on yield and component characters in rapeSeed and mustard cultivars. Journal of Biological Sciences, 1(9):840-842.

Julier, B., S. Flajoulot, P. Barre and G. Cardinet (2003). Construction of two genetic linkage maps in cultivated tetraploid alfalfa (Medicago sativa) using microsatellite and AFLP markers. BMC Plant Biol. 3: 9.

Lin, J., J. Kuo, J. Ma, J. A. Saunders, H. S. Beard, M. H. MacDonald, W. Kenworthy, G. N. Ude and B. F. Matthews (1996). Identification of molecular markers in soybean comparing RFLP, RAPD and AFLP DNA mapping techniques. Plant Mol. Biol. Rep., 14: 156-169.

Liu, Z.P., Q. C. Yang, T. M. Hu and L. F. Yan (2006). Genetic diversity of autotetraploid alfalfa with different salt-tolerant traits based on SSR marker analysis. Acta Agron. Sin. 32: 630-632.

Longenecker, D. E. and P. J. Lyerly, (1974). Control of soluble salts in farming and gardening: B-876. Texas Agricultural Experiment Station. Texas A\&M Univ. Publication. College Station, TX.

Mengoni, A., C. Ruggini, G. G. Vendramin and M. Bazzicalupo (2000). Chloroplast microsatellite variation in tretraploid alfalfa. Plant Breed. 119: 509-512.

Monirifar H., M. Valizadeh, R. Mohammadian, M. Abedi and O. Milani (2004). Variation for salt tolerance in five alfalfa cultivares. International scientific symposium, Ganja, Azarbayjan.

Moreira, A. and N.K. Fageria (2010). Liming influence on soil chemical properties, nutritional status and yield of alfalfa grown in acid soil. R. Bas. Ci. Solo, 34, p:1231-1239.

Munns, R. (2005). Response of crops to salinity. In Abstracts, International Salinity Forum Proceedings, pp. 339, Riverside, CA. 25-27 Apr. 2005. Riverside, CA.

Munns, R., and M. Tester (2008). Mechanisms of salinity tolerance. Annu. Rev. Plant Biol. 59:651-681. doi:10.1146/annurev. arplant. 59.032607.092911

Nei, M. and Li, W.H. (1979). Mathematical model for studying genetic variation in terms of restriction endonucleases. Proc. Natl. Acad. Sci. 76:52695273.

Neqi, M. S., A. Singh and M. Lakshmikumaran (2000). Genetic variation and relationship among and within Withania species as revealed by AFLP markers. Genome, 43: 975-980.

Oushy, H.S., M.M. Abdel-Galil and N.M. Hamd (2007), Performance of local and exotic alfalfa cultivars under different environmental conditions in Egypt. Egypt. J. Agric. Res., 85, 2201-2217.

Reddy, M. P, N. Sarla and E. A. Siddiq (2002). Inter simple sequence repeat (ISSR) polymorphism and its application in plant breeding. Euphytica, 128(1):9-17. 
Rumbaugh M. D. and B. M. Pendery (1990). Germination salt resistance of alfalfa (Medicago sativa L.) germplasm in relation to subspecies and centers of diver-sity. Plant Soil 124, 47-51.

SAS (2004). SAS Statistics User's Guide. Release 9.2. SAS Institute, Cary, NC. USA.

Said, O. A. M. (2005). Genetic characterization of some medicinal plants. MSc. Thesis, Fac. Agric. Ain Shams Univ., Egypt.

Shaban, Kh, A. and A. A. El-Sherife (2007). Evaluation of alfalfa productivity and its response to biofertilizer, mineral nitrogen and sulphure under saline condition in newly reclaimed area. Egypt. J. Soil Sci., 47, (4): 347 -366.

Sheard, R. W. (2007). Fertilizer practices for alfalfa production. Published in Plant and fertilizer.
Department Land Source Science, Univ. of Guelph, (2) : 1-5.

Soya, H., R. Avcioglu and H. Geren (2004). Forage crops, Hasad Press, Turkey, 223p (in Turkish).

Wei, Z. W. (2004). DNA fingerprint of Medicago sativa variety genomes using SSR, ISSR and RAPD. Acta Prataculturae Sinica, 13: 62-67.

Wenzel, G. (1992). Application of unconventional technique in classical plant production. In: $\mathrm{M}$. W. Fowher, G. S. Warren and M. Young (Eds). Plant Biotechnology. Pergaman Press, Oxford. New York- Seoul, Tokyo, pp 259.

Williams, J.G.K., A.R. Kubelik, K.J. Livak, J.A. Raflaski and S.V. Tingey (1990). DNA polymorphism amplified by arbitrary primers are useful as genetic markers. Nucleic Acids Res., 18: 6531-6535. 